\title{
Engineered Cytochrome c-Catalyzed Lactone-Carbene B-H Insertion
}

\author{
Kai Chen ${ }^{\mathrm{a}}$ (1) \\ Xiongyi Huang ${ }^{a}($ C) \\ Shuo-Qing Zhang ${ }^{b}(\mathbb{D}$ \\ Andrew Z. Zhou ${ }^{\text {a }}$ \\ S. B. Jennifer Kan ${ }^{a}($ (D) \\ Xin Hong*b (i) \\ Frances H. Arnold*a (D) \\ a Division of Chemistry and Chemical Engineering 210-41, California \\ Institute of Technology, Pasadena, CA 91125, USA \\ frances@cheme.caltech.edu \\ ${ }^{b}$ Department of Chemistry, Zhejiang University, Hangzhou, Zhejiang \\ 31007, P. R. of China \\ hxchem@zju.edu.cn
}

Published as part of the 30 Years SYNLETT - Pearl Anniversary Issue

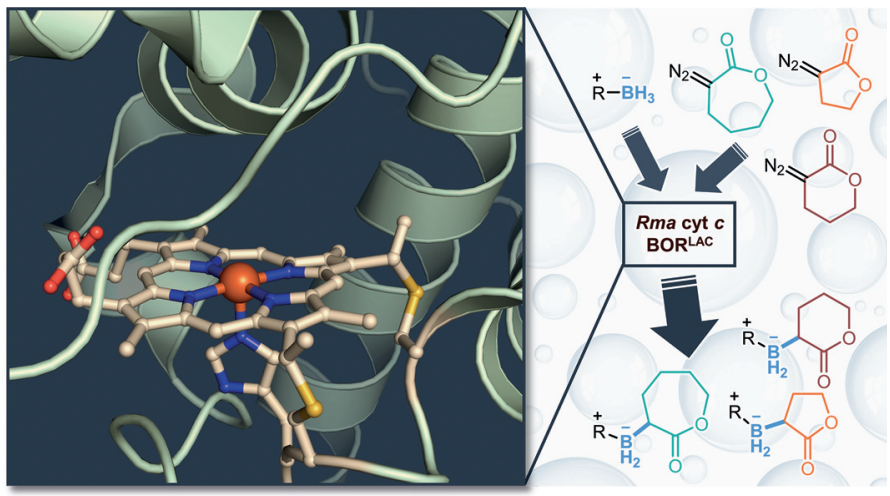

Received: 26.11.2018

Accepted after revision: 05.01.2019

Published online: 14.01 .2019

DOI: 10.1055/s-0037-1611662; Art ID: st-2018-b0769-I

License terms: (C)

Abstract Previous work has demonstrated that variants of a heme protein, Rhodothermus marinus cytochrome c (Rma cyt c), catalyze abiological carbene boron-hydrogen $(B-H)$ bond insertion with high efficiency and selectivity. Here we investigated this carbon-boron bondforming chemistry with cyclic, lactone-based carbenes. Using directed evolution, we obtained a Rma cyt $c$ variant BOR $^{\text {LAC }}$ that shows high selectivity and efficiency for $\mathrm{B}-\mathrm{H}$ insertion of 5 - and 6 -membered lactone carbenes (up to 24,500 total turnovers and 97.1:2.9 enantiomeric ratio). The enzyme shows low activity with a 7-membered lactone carbene. Computational studies revealed a highly twisted geometry of the 7membered lactone carbene intermediate relative to 5- and 6-membered ones. Directed evolution of cytochrome $c$ together with computational characterization of key iron-carbene intermediates has allowed us to expand the scope of enzymatic carbene $\mathrm{B}-\mathrm{H}$ insertion to produce new lactone-based organoborons.

Key words cytochrome c, carbene, organoboron, lactones, biocatalyst, directed evolution

The significant role of organoboron chemistries ${ }^{1-3}$ in synthetic methodologies is exemplified by alkene hydroboration $^{4,5}$ and Suzuki cross-coupling, ${ }^{6,7}$ whose enormous footprints in synthetic chemistry have been recognized by Nobel Prizes. In addition, organo-boronic acids or -borates ${ }^{8}$ can act as transition-state-analog inhibitors in biological systems and are useful functionalities in chemotherapeutics $^{9}$ and other biologically active molecules. ${ }^{10}$ The broad applications of organoboron compounds have prompted chemists to develop efficient, selective and modular synthetic platforms for installing boron motifs onto carbon backbones. One major class of methods for forming carbonboron $(\mathrm{C}-\mathrm{B})$ bonds relies on transition-metal-catalyzed $\mathrm{B}-\mathrm{H}$ bond insertion of carbenes (Figure 1A), ${ }^{11-18}$ as introduced by Curran and co-workers. Recently, the Arnold laboratory developed the first biocatalytic system for this transformation using engineered variants of cytochrome $c$ from the Gram-negative, thermohalophilic bacterium Rhodothermus marinus (Rma cyt $c$ ). ${ }^{19}$ The laboratory-evolved enzymes exhibited very high efficiency (up to 15,300 turnovers and $6,100 \mathrm{~h}^{-1}$ turnover frequency) and enantioselectivity (up to 99:1 enantiomeric ratio) with different carbenes and boranes (Figure 1B).

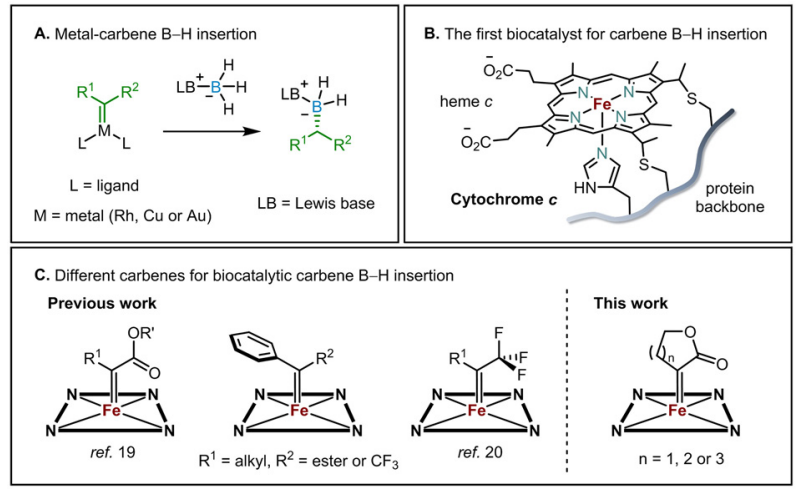

Figure 1 A . Catalytic carbene B-H insertion. B. A hemeprotein biocatalyst for carbene B-H insertion based on Rma cytochrome $c$. C. Carbenes used for biocatalytic carbene $\mathrm{B}-\mathrm{H}$ insertion

To expand the catalytic range of this enzymatic C-B bond-forming platform, we have engineered Rma cyt $c$ to accept structurally different carbenes. In previous work, we typically used $\alpha$-ester-substituted diazo compounds as carbene precursors, ${ }^{19}$ but we recently demonstrated that $\mathrm{Rma}$ cyt $c$ mutants can be tuned to use a spectrum of $\alpha$-trifluoromethyl- $\alpha$-alkyl diazo compounds to furnish a wide array of 
chiral $\alpha$-trifluoromethylated organoborons (Figure 1C). ${ }^{20}$ We were curious whether cyclic carbene moieties ${ }^{21}$ can also be used by Rma cyt $c$, despite significant structural differences compared to the acyclic carbenes used in previous work. ${ }^{19-26}$

We started this investigation of cyclic carbenes using five-membered lactone diazo compound $\mathbf{1}$ (see Figure 3 ) as the carbene precursor. With such a rigid structure, the putative iron-porphyrin carbene (IPC) intermediate is expected to have different conformational properties and potentially distinct electronic features compared to acyclic carbenes, such as the one derived from $\alpha$-methyl ethyl diazoacetate (Me-EDA). Recent work by our group revealed the crystal structure of the Me-EDA-derived IPC intermediate ${ }^{27}$ in a triple mutant of Rma cyt $c$ (V75T M100D M103E (TDE)) evolved in the laboratory for $\mathrm{Si}-\mathrm{H}$ bond insertion. ${ }^{26}$ Experiments indicated a singlet electronic state of this iron carbene species IPC1, which is in line with the computational result that open/closed-shell singlets are the dominant electronic states (Figure 2).
We used density functional theory (DFT) calculations to assess the electronic states of the lactone-based IPC2 (also using the simplified model of the protein IPC). ${ }^{21,27-30}$ As we expected, IPC2 features a near-planar geometry with a very small dihedral angle $\mathrm{d}(\mathrm{Fe}-\mathrm{C}-\mathrm{C}-\mathrm{O})\left(<13^{\circ}\right)$ in all electronic states, which is very different from the acyclic IPC1 with $\mathrm{d}(\mathrm{Fe}-\mathrm{C}-\mathrm{C}-\mathrm{O})$ of nearly $90^{\circ}$ in singlets. The small dihedral angle renders the singlet states less stable due to strong repulsion between fully occupied orbitals and thus significantly changes the energy levels of the electronic states of the IPC.

We wanted to know how the different structural and electronic properties of this intermediate affect carbene $\mathrm{B}-\mathrm{H}$ insertion. We thus tested the borylation reaction using the five-membered lactone diazo compound $\mathbf{1}$ and an $\mathrm{N}$-heterocyclic carbene (NHC)-stabilized borane as substrates in the presence of whole $E$. coli bacteria expressing engineered variants of Rma cyt $c$, starting with those obtained during directed evolution for borylation with acyclic carbene precursors (e.g., Me-EDA) (Figure 3). We were pleasantly surprised to see that wild-type Rma cyt $c$ exhib-

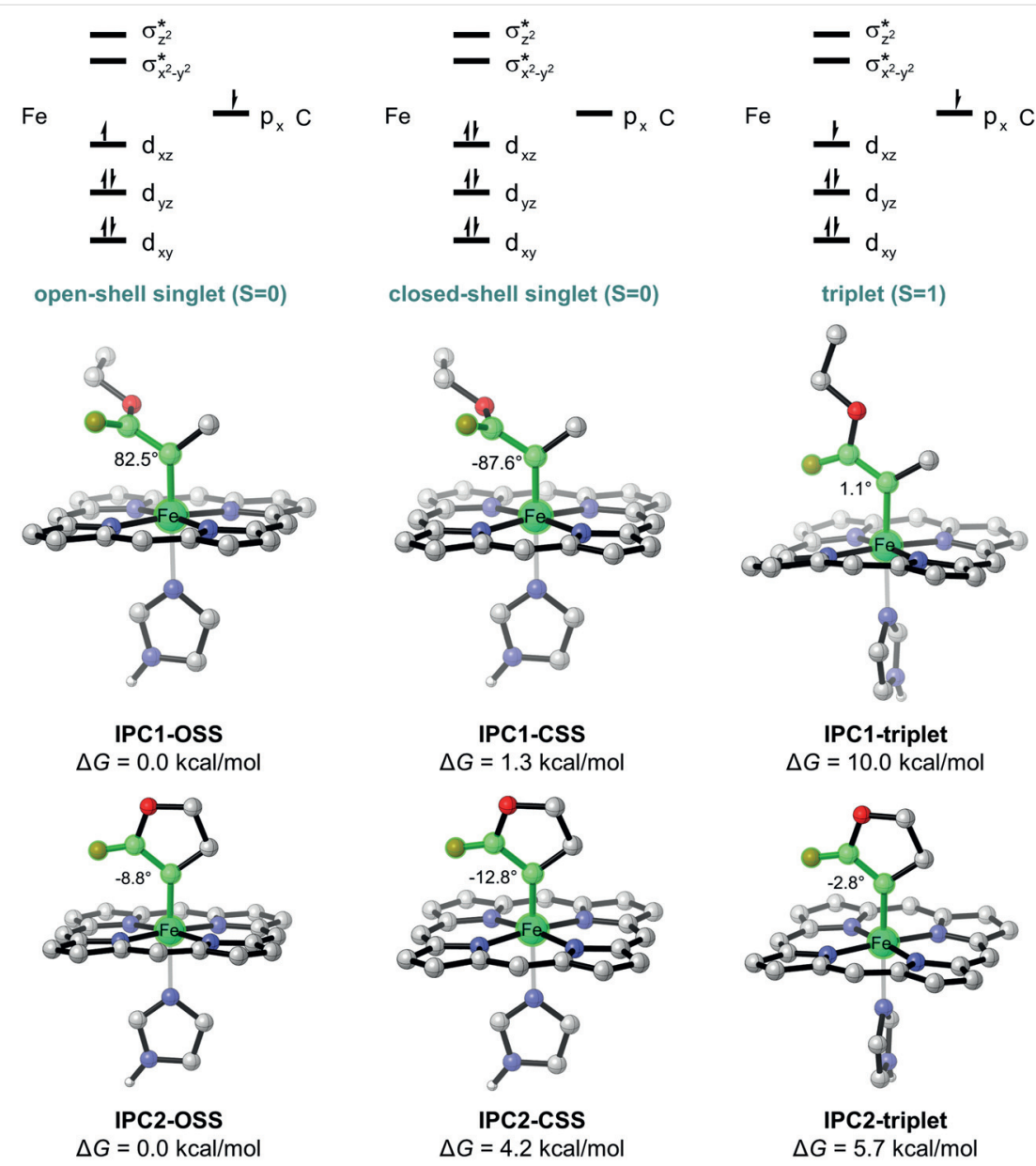

Figure 2 Electronic states of acyclic IPC1 and cyclic IPC2 intermediates. The Gibbs free energies were obtained at the B3LYP-D3(BJ)/def2-TZVPP//B3LYP/def2-SVP level. OSS = open-shell singlet, CSS = closed-shell singlet 
ited high efficiency for lactone carbene B-H insertion, with 960 total turnovers (TTN) and 70\% gas chromatography (GC) yield. The enantioselectivity, however, was poor, with only a 68:32 enantiomeric ratio (e.r.). A distal axial-ligand M100D mutation, previously discovered to facilitate both carbene Si-H and B-H insertion, ${ }^{19,26}$ improved the yield, but did not improve the enantiocontrol of this reaction. Residue V75 in an $\alpha$-helix region was previously shown to affect carbene orientation. ${ }^{19,20}$ Screening of M100D variants containing mutations at V75 identified M100D V75R as the most selective, with 93.3:6.7 e.r., whereas $V 75 T / C / K / P / G$ mutations resulted in poor to moderate enantioselectivities. An additional M103V mutation led to even more precise stereochemical control, giving an e.r. of 94.9:5.1 (Figure 3).

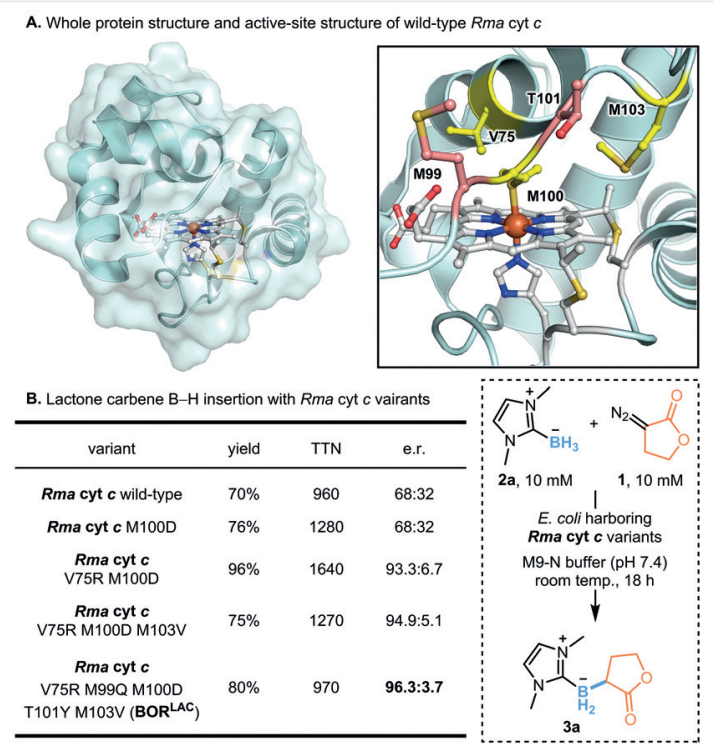

Figure $3 \mathbf{A}$. Whole protein structure and active-site structure of wildtype Rma cyt c (PDB: 3CP5, ref. 31). B. Yields and e.r. values of selected Rma cyt $c$ variants for $\mathrm{B}-\mathrm{H}$ insertion. Reactions were conducted in quadruplicate: suspensions of $E$. coli expressing Rma cyt c variants $\left(\mathrm{OD}_{600}=20\right)$, $10 \mathrm{mM}$ borane $2 \mathrm{a}, 10 \mathrm{mM}$ lactone diazo 1 , and 5 vol\% acetonitrile in M9-N buffer ( $\mathrm{pH} 7.4$ ) at room temperature under anaerobic conditions for 18 hours. TTN refers to the molar ratio of total desired product, as quantified by gas chromatography-mass spectrometry (GC-MS) using trimethoxybenzene as internal standard, to total heme protein. Enantiomeric ratio (e.r.) was determined by chiral high-performance liquid chromatography (HPLC)

To increase the enantioselectivity of lactone-carbene B$\mathrm{H}$ insertion, we subjected the Rma cyt $c$ V75R M100D M103V (RDV) variant to site-saturation mutagenesis, targeting active-site amino acid residues which are close to the iron center in wild-type Rma cyt $c$ (within $10 \AA$ ). It is known that the residues residing on the flexible front loop are important for controlling the structure of the heme pocket, which is presumably the active site for this novel function (Figure $3 \mathrm{~A}$ ). ${ }^{27}$ Consequently, introducing suitable mutations on this loop may help to orient the iron-carbene intermediate or tune the approach of the borane substrate and lead to desired enantioselectivity. A double-site-saturation mutagenesis library at residues M99 and T101 was cloned using the 22-codon-trick protocol ${ }^{32}$ and screened as whole-cell catalysts in four 96-well plates for improved borylation enantioselectivity. Double mutant M99Q T101Y $\left(\mathbf{B O R}^{\text {LAC}}\right)$ was identified to exhibit higher selectivity (96.3:3.7 e.r.) and good catalytic efficiency (970 TTN, 80\% GC yield).

With an efficient and selective borylating variant $\mathbf{B O R}^{\mathbf{L A C}}$ in hand, we then assessed the scope of boranes that this platform can use (Figure 4A). Boranes without stabilizing groups are highly reactive and unstable in aqueous conditions. Lewis bases, such as ethers, amines, phosphines and NHCs, are generally used as good stabilizing groups for free boranes. ${ }^{33}$ Considering the biocompatibility and cell permeability of the borane reagents, NHC-stabilized boranes turned out to be suitable candidates for this borylation platform. ${ }^{34}$ Indeed, borane complexes stabilized by NHCs featuring different electronic properties, steric hindrance and/or lipophilicity all served as good substrates for the target borylation reaction, furnishing the desired products with up to 1160 TTN and enantioselectivities up to 97.1:2.9 e.r. For instance, fluorine-containing alkyl groups (e.g., 2c), which are electron-withdrawing and usually exhibit very different lipophilicity and hydrophilicity relative to general aliphatic alkyl groups, were found to be compatible with the whole-cell reaction conditions.

To explore the longevity of the biocatalyst, we tried portionwise addition of the two substrates. Every 1.5 hours, we added an additional aliquot corresponding to $12.5 \mathrm{mM}$ of each substrate to the reaction. Over 20 additions, we observed continuous and steadily increasing product formation, which indicates that the catalyst maintained function over 30 hours (Figure 4C). However, we did notice that enantioselectivities decreased. Covalent modification of the protein backbone by carbene species and non-covalent binding of borane substrate or product to the protein may cause structural changes that compromise stereocontrol. ${ }^{35}$ Further reaction engineering and optimization, such as using a flow system to maintain consistent concentrations of reagents, may be able to address this selectivity drop.

Given that the 5-membered cyclic lactone-carbene worked so well for this biocatalytic B-H insertion, we wondered whether other cyclic carbenes, particularly lactonecarbenes with different ring sizes, would also be accepted. The 6- and 7-membered lactone diazos 4 and 6 were readily prepared from the corresponding lactones and used as cyclic carbene precursors for testing $\mathrm{B}-\mathrm{H}$ insertion using variant $\mathbf{B O R}^{\mathbf{L A C}}$ (Figure 4A). The 6-membered lactone-carbene showed high reactivities (up to 1190 TTN and 96.1:3.9 e.r.) for the desired borylation with three different borane substrates. Additionally, enzymatic borylation with both 5- and 6-membered lactone carbenes was readily scalable to millimole level, affording the desired products in high isolated yields (Figure 4B). However, with one additional carbon in 


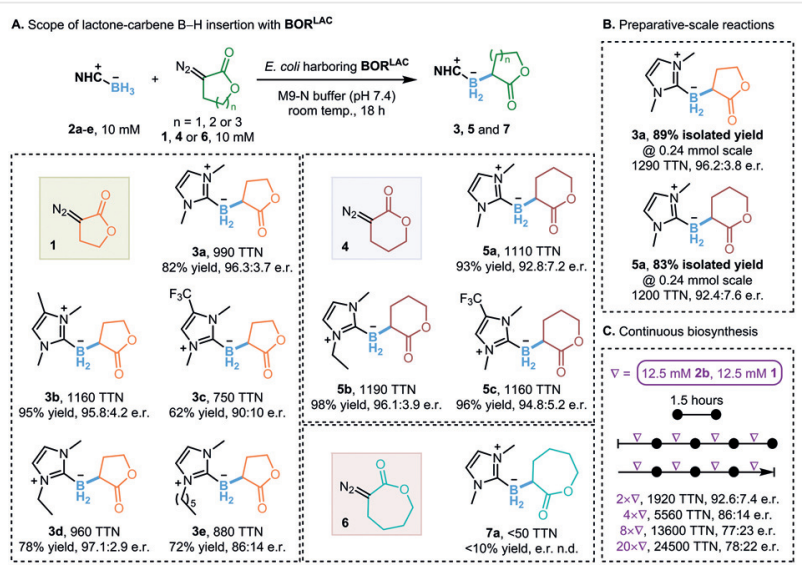

Figure 4 A . Scope of lactone-carbene B-H insertion with BOR ${ }^{\mathrm{LAC}}$. Reactions were conducted in quadruplicate: suspension of $E$. coli expressing Rma cyt c variant BOR ${ }^{\mathrm{LAC}}\left(\mathrm{OD}_{600}=20\right), 10 \mathrm{mM}$ borane $2,10 \mathrm{mM}$ lactone diazo 1, $\mathbf{4}$ or $\mathbf{6}$, and 5 vol\% acetonitrile in M9-N buffer ( $\mathrm{pH} 7.4)$ at room temperature under anaerobic conditions for 18 hours. TTN refers to the total desired product, as quantified by GC-MS using trimethoxybenzene as internal standard, divided by total heme protein. Enantiomeric ratio (e.r.) was determined by chiral HPLC. B. Preparativescale synthesis of organoborons. Reaction conditions: suspension of $E$. coli expressing Rma cyt $c$ variant $\mathbf{B O R}^{\mathrm{LAC}}\left(\mathrm{OD}_{600}=15\right), 12 \mathrm{mM}$ borane 2a, $12 \mathrm{mM}$ lactone diazo 1 or $\mathbf{4}, 50 \mathrm{mM}$ D-glucose and 6 vol\% acetonitrile in M9-N buffer ( $\mathrm{pH} 7.4$ ) at room temperature under anaerobic conditions for 18 hours. Reactions were set up in quadruplicate and organoboron products were isolated from the combined reaction replicates. C. Enzymatic synthesis of organoborons with portionwise addition of substrates. Reactions were conducted in duplicate using the same reaction conditions as in $\mathbf{A}$. above, except for using $2.5 \mathrm{M}$ solution stocks of borane $\mathbf{2} \mathbf{b}$ and lactone diazo $\mathbf{1}$ (one portion $=2 \mu \mathrm{L}$ of each substrate stock)

the ring, the 7-membered lactone-carbene behaved in a completely different manner: $\mathbf{B O R}^{\mathbf{L A C}}$ exhibited only low activity with this carbene precursor ( $<50$ TTN).

To understand the origins of this dramatic impact of ring size on Rma cyt c-catalyzed lactone-carbene B-H insertion chemistry, we employed DFT calculations to compare the structures and the electronic properties of three lactonetype IPCs. Unlike 5-membered lactone-based IPC2, which takes on a rigid planar structure, 6 -membered lactone-carbene IPC3 showed a slightly flexible structure with a dihedral angle $\mathrm{d}(\mathrm{Fe}-\mathrm{C}-\mathrm{C}-\mathrm{O})$ of $60^{\circ}$ in the ground OSS state, while its triplet state still possesses a near-planar geometry (Figure 5). However, 7-membered lactone IPC4 takes on highly twisted conformations with $\mathrm{d}(\mathrm{Fe}-\mathrm{C}-\mathrm{C}-\mathrm{O})$ from $47^{\circ}$ to $73^{\circ}$ in all electronic states. ${ }^{36}$ It is apparent that none of the electronic states in IPC4 shares a similar structure with IPC2. This may explain why $\mathbf{B O R}^{\mathbf{L A C}}$, which was evolved for the 5membered lactone carbene, did not exhibit high reactivity towards borylation with the 7-membered lactone carbene. But this does not necessarily mean that Rma cyt $c$ cannot be engineered to accommodate the 7-membered lactone car- bene for B-H insertion; further engineering using $\mathbf{B O} \mathbf{R}^{\mathbf{L A C}}$ as a starting template could well lead to variants with improved reactivity on this 7-membered lactone carbene.
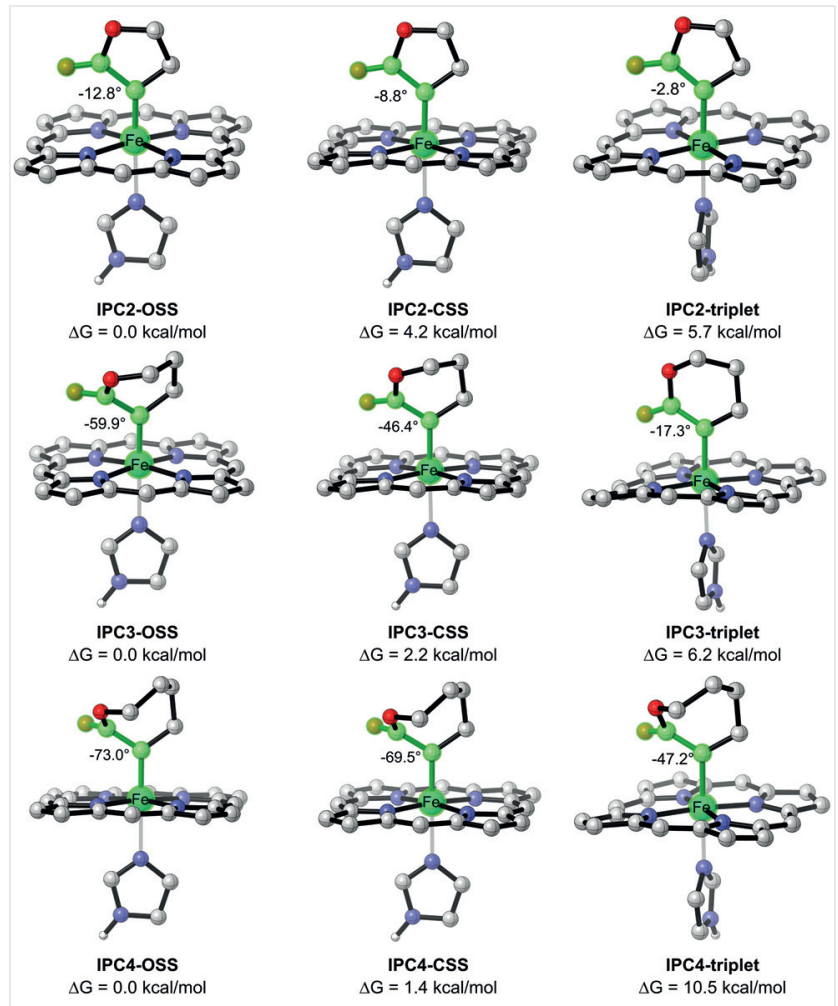

Figure 5 Comparison of 5-, 6- and 7-membered lactone-based IPCs. The Gibbs free energies were obtained at the B3LYP-D3(BJ)/def2-TZVPP//B3LYP/def2-SVP level

In conclusion, we have expanded the scope of carbenes for biocatalytic B-H insertion chemistry to include cyclic lactone carbenes. ${ }^{37}$ With further development of Rma cyt $c$ based biocatalytic platforms, we accessed a range of organoborons at preparative scales and with unprecedented catalytic efficiencies (up to 24,500 TTN) and high enantioselectivities (up to 97.1:2.9 e.r.). Computational studies provided insights into the conformations and electronic states of cyclic carbene intermediates with different ring sizes. This mechanistic understanding together with the new biocatalyst variants identified should promote further expansion of carbene scope for borylation and other carbenetransfer reactions.

\section{Funding Information}

Financial support from the NSF Division of Molecular and Cellular Biosciences grant MCB-1513007, National Natural Science Foundation of China (21702182), Zhejiang University, the Chinese "Thousand Youth Talents Plan", and the "Fundamental Research Funds for the Central Universities" is gratefully acknowledged. K.C. thanks the Resnick Sustainability Institute at Caltech for fellowship support. X.H. is 
supported by an NIH pathway to independence award (grant K99GM129419).

\section{Acknowledgment}

A.Z.Z. thanks the Caltech SURF program. Calculations were performed on the high-performance computing system at the Department of Chemistry, Zhejiang University. We thank R. D. Lewis and R. K. Zhang for helpful discussions and comments. We also thank the Caltech Mass Spectrometry Laboratory.

\section{Supporting Information}

Supporting information for this article is available online at https://doi.org/10.1055/s-0037-1611662.

\section{References}

(1) Fyfe, J. W. B.; Watson, A. J. B. Chem 2017, 3, 31.

(2) Leonori, D.; Aggarwal, V. K. Acc. Chem. Res. 2014, 47, 3174.

(3) Lennox, A. J. J.; Lloyd-Jones, G. C. Chem. Soc. Rev. 2014, 43, 412.

(4) Brown, H. C.; Ramachandran, P. V. Pure Appl. Chem. 1991, 63, 307.

(5) Brown, H. C.; Jadhav, P. K.; Mandal, A. K. Tetrahedron 1981, 37, 3547.

(6) Miyaura, N.; Suzuki, A. Chem. Rev. 1995, 95, 2457.

(7) Martin, R.; Buchwald, S. L. Acc. Chem. Res. 2008, 41, 1461.

(8) Boronic Acids: Preparation and Applications in Organic Synthesis and Medicine; Hall, D. G., Ed.; Wiley-VCH: Weinheim, 2005.

(9) Das, B. C.; Thapa, P.; Karki, R.; Schinke, C.; Das, S.; Kambhampati, S.; Banerjee, S. K.; Veldhuizen, P. V.; Verma, A.; Weiss, L. M.; Evans, T. Future Med. Chem. 2013, 5, 653.

(10) Dembitsky, V. M.; Al Quntar, A. A.; Srebnik, M. Chem. Rev. 2011, 111, 209.

(11) Li, X.; Curran, D. P. J. Am. Chem. Soc. 2013, 135, 12076.

(12) Cheng, Q.-Q.; Zhu, S.-F.; Zhang, Y.-Z.; Xie, X.-L.; Zhou, Q.-L.J. Am. Chem. Soc. 2013, 135, 14094.

(13) Chen, D.; Zhang, X.; Qi, W.-Y.; Xu, B.; Xu, M.-H. J. Am. Chem. Soc. 2015, 137, 5268.

(14) Hyde, S.; Veliks, J.; Liégault, B.; Grassi, D.; Taillefer, M.; Gouverneur, V. Angew. Chem. Int. Ed. 2016, 55, 3785.

(15) Yang, J.-M.; Li, Z.-Q.; Li, M.-L.; He, Q.; Zhu, S.-F.; Zhou, Q.-L. J. Am. Chem. Soc. 2017, 139, 3784.

(16) Pang, Y.; He, Q.; Li, Z.-Q.; Yang, J.-M.; Yu, J.-H.; Zhu, S.-F.; Zhou, Q.-L.J. Am. Chem. Soc. 2018, 140, 10663.

(17) Allen, T. H.; Kawamoto, T.; Gardner, S.; Geib, S. J.; Curran, D. P. Org. Lett. 2017, 19, 3680.

(18) Yang, J.-M.; Zhao, Y.-T.; Li, Z.-Q.; Gu, X.-S.; Zhu, S.-F.; Zhou, Q.-L. ACS Catal. 2018, 8, 7351.

(19) Kan, S. B. J.; Huang, X.; Gumulya, Y.; Chen, K.; Arnold, F. H. Nature 2017, 552, 132.

(20) Huang, X.; Garcia-Borràs, M.; Miao, K.; Kan, S. B. J.; Zutshi, A.; Houk, K. N.; Arnold, F. H. ChemRxiv 2018, DOI: 10.26434/chemrxiv.7130852.

(21) Chen, K.; Zhang, S.-Q.; Brandenberg, O. F.; Hong, X.; Arnold, F. H. J. Am. Chem. Soc. 2018, 140, 16402.

(22) Coelho, P. S.; Brustad, E. M.; Kannan, A.; Arnold, F. H. Science 2013, 339, 307.

(23) Coelho, P. S.; Wang, Z. J.; Ener, M. E.; Baril, S. A.; Kannan, A.; Arnold, F. H.; Brustad, E. M. Nat. Chem. Biol. 2013, 9, 485.
(24) Brandenberg, O. F.; Fasan, R.; Arnold, F. H. Curr. Opin. Biotechnol. 2017, 47, 102.

(25) Chen, K.; Huang, X.; Kan, S. B. J.; Zhang, R. K.; Arnold, F. H. Science 2018, 360, 71.

(26) Kan, S. B. J.; Lewis, R. D.; Chen, K.; Arnold, F. H. Science 2016, $354,1048$.

(27) Lewis, R. D.; Garcia-Borras, M.; Chalkley, M. J.; Buller, A. R.; Houk, K. N.; Kan, S. B. J.; Arnold, F. H. Proc. Natl. Acad. Sci. U.S.A. 2018, 115, 7308.

(28) Khade, R. L.; Fan, W.; Ling, Y.; Yang, L.; Oldfield, E.; Zhang, Y. Angew. Chem. Int. Ed. 2014, 53, 7574.

(29) Sharon, D. A.; Mallick, D.; Wang, B.; Shaik, S. J. Am. Chem. Soc. 2016, $138,9597$.

(30) Wei, Y.; Tinoco, A.; Steck, V.; Fasan, R.; Zhang, Y. J. Am. Chem. Soc. 2018, 140, 1649.

(31) Stelter, M.; Melo, A. M. P.; Pereira, M. M.; Gomes, C. M.; Hreggvidsson, G. O.; Hjorleifsdottir, S.; Saraiva, L. M.; Teixeira, M.; Archer, M. Biochemistry 2008, 47, 11953.

(32) Kille, S.; Acevedo-Rocha, C. G.; Parra, L. P.; Zhang, Z.-G.; Opperman, D. J.; Reetz, M. T.; Acevedo, J. P. ACS Synth. Biol. 2013, 2, 83.

(33) Yang, J.-M.; Li, Z.-Q.; Zhu, S.-F. Chin. J. Org. Chem. 2017, 37, 2481.

(34) Tehfe, M.-A.; Monot, J.; Malacria, M.; Fensterbank, L.; Fouassier, J. P.; Curran, D. P.; Lacôte, E.; Lalevée, J. ACS Macro Lett. 2012, 1, 92.

(35) Renata, H.; Lewis, R. D.; Sweredoski, M. J.; Moradian, A.; Hess, S.; Wang, Z. J.; Arnold, F. H. J. Am. Chem. Soc. 2016, 138, 12527.

(36) DeAngelis, A.; Dmitrenko, O.; Fox, J. M. J. Am. Chem. Soc. 2012 $134,11035$.

\section{(37) General Procedure}

To a $20 \mathrm{~mL}$ vial were added a suspension of $E$. coli expressing Rma cytochrome $c$ variant $\mathbf{B O R}^{\mathrm{LAC}}\left(5 \mathrm{~mL}, \mathrm{OD}_{600}=15\right)$, borane $(150 \mu \mathrm{L}$ of a $400 \mathrm{mM}$ stock solution in MeCN, $0.06 \mathrm{mmol})$, lactone diazo compound ( $150 \mu \mathrm{L}$ of a $400 \mathrm{mM}$ stock solution in $\mathrm{MeCN}, 0.06 \mathrm{mmol}$ ), and D-glucose (50 mM) in M9-N buffer (pH 7.4) under anaerobic conditions. The vial was capped and shaken ( $480 \mathrm{rpm}$ ) at room temperature for $18 \mathrm{~h}$. Reactions were set up in quadruplicate. Upon completion, reactions in replicate were combined and transferred to $50 \mathrm{~mL}$ centrifuge tubes. The reaction vials were washed with water $(2 \times 2 \mathrm{~mL})$ followed by a mixed organic solvent (hexane/ethyl acetate $=1: 1,3 \times 2 \mathrm{~mL}$ ). The washing solution was combined with the reaction mixture in the centrifuge tubes. An additional $15 \mathrm{~mL}$ of hexane/ethyl acetate solvent was added to every tube. The tube was then vortexed $(3 \times 1 \mathrm{~min})$ and shaken vigorously, and centrifuged $(5,000 \times \mathrm{g}, 5 \mathrm{~min})$. The organic layer was separated and the aqueous layer was subjected to three more rounds of extraction. The organic layers were combined, dried over $\mathrm{Na}_{2} \mathrm{SO}_{4}$ and concentrated under reduced pressure. Purification by silica gel column chromatography with hexane/(ethyl acetate/acetone $3: 7)$ as eluent afforded the desired lactone-based organoboranes. Enantiomeric ratio (e.r.) was measured by chiral HPLC. TTN was calculated based on measured protein concentration and isolated product yield. Product 3a was obtained as a white solid (41.4 mg, 89\%, $1290 \mathrm{TTN}) .{ }^{1} \mathrm{H}$ NMR (400 MHz, $\mathrm{CDCl}_{3}$ ): $\delta=6.83(\mathrm{~s}, 2 \mathrm{H}), 4.45$ (dddd, $J=10.7,8.1,6.8,1.0 \mathrm{~Hz}, 1 \mathrm{H}$ ), 4.27 (tq, $J=9.0,1.1 \mathrm{~Hz}, 1 \mathrm{H}), 3.83-3.69(\mathrm{~m}, 6 \mathrm{H}), 2.53-2.25(\mathrm{~m}, 1 \mathrm{H})$, 2.01-1.93 (m, $1 \mathrm{H}), 1.88-1.80(\mathrm{~m}, 1 \mathrm{H}), 1.79-1.16(\mathrm{~m}, 2 \mathrm{H}) ;{ }^{13} \mathrm{C}$ $\operatorname{NMR}\left(101 \mathrm{MHz}, \mathrm{CDCl}_{3}\right): \delta=187.91,120.62,67.86,36.15,30.86$; ${ }^{11} \mathrm{~B}$ NMR $\left(128 \mathrm{MHz}, \mathrm{CDCl}_{3}\right): \delta=-27.08(\mathrm{t}, J=89.6 \mathrm{~Hz})$; HRMS $(\mathrm{FAB}+): m / z\left[\left(\mathrm{M}+\mathrm{H}^{+}\right)-\mathrm{H}_{2}\right]$ calcd for $\mathrm{C}_{9} \mathrm{H}_{14} \mathrm{O}_{2} \mathrm{~N}_{2} \mathrm{~B}:$ 193.1148; found: 193.1144; Chiral HPLC (Chiralpak IC, $40 \% i$-PrOH in hexane, flow rate: $1.5 \mathrm{~mL} / \mathrm{min}$, temperature: $32{ }^{\circ} \mathrm{C}, \lambda=235 \mathrm{~nm}$ ): $t_{\mathrm{R}}($ major $)=12.857 \mathrm{~min}, t_{\mathrm{R}}($ minor $)=10.991 \mathrm{~min}$; 96.2:3.8 e.r. 